\title{
Long-term outcomes among octogenarians with aneurysmal subarachnoid hemorrhage
}

\author{
Hormuzdiyar Dasenbrock, MD, ${ }^{1,2}$ William B. Gormley, MD, MPH, MBA, ${ }^{1,2}$ Yoojin Lee, MS, MPH, ${ }^{3}$ \\ Vincent Mor, PhD, ${ }^{3}$ Susan L. Mitchell, MD, MPH, ${ }^{2,4}$ and Corey R. Fehnel, MD, MPH ${ }^{2,4,5}$
}

\begin{abstract}
${ }^{1}$ Department of Neurosurgery, Brigham and Women's Hospital; ${ }^{2 H}$ arvard Medical School; ${ }^{4}$ Institute for Aging Research, Hebrew SeniorLife; ${ }^{5}$ Department of Neurology, Beth Israel Deaconess Medical Center, Boston, Massachusetts; and ${ }^{3}$ Department of Health Services, Policy \& Practice, Brown University School of Public Health, Providence, Rhode Island
\end{abstract}

\begin{abstract}
OBJECTIVE Data evaluating the long-term outcomes, particularly with regard to treatment modality, of aneurysmal subarachnoid hemorrhage (SAH) in octogenarians are limited. The primary objectives were to evaluate the disposition (living at home vs institutional settings) and analyze the predictors of long-term survival and return to home for octogenarians after SAH.

METHODS Data pertaining to patients age 80 and older who underwent microsurgical clipping or endovascular coiling for SAH were extracted from 100\% nationwide Medicare inpatient claims and linked with the Minimum Data Set (20082011). Patient disposition was tracked for 2 years after index SAH admission. Multivariable logistic regression stratified by aneurysm treatment modality, and adjusted for patient factors including SAH severity, evaluated predictors of return to home at 60 and 365 days after SAH. Survival 365 days after SAH was analyzed with a multivariable Cox proportional hazards model.
\end{abstract}

RESULTS A total of 1298 cases were included in the analysis. One year following SAH, $56 \%$ of the patients had died or were in hospice care, $8 \%$ were in an institutional post-acute care setting, and $36 \%$ had returned home. Open microsurgical clipping (adjusted hazard ratio [aHR] 0.67, 95\% confidence interval [Cl] 0.54-0.81), male sex (aHR 0.70, 95\% $\mathrm{Cl} 0.57-0.87$ ), tracheostomy (aHR $0.63,95 \% \mathrm{Cl} 0.47-0.85$ ), gastrostomy (aHR 0.60, 95\% Cl 0.48-0.76), and worse SAH severity (aHR $0.94,95 \% \mathrm{Cl} 0.92-0.97$ ) were associated with reduced likelihood of patients ever returning home. Older age (aHR 1.09, 95\% Cl 1.05-1.13), tracheostomy (aHR 2.06, 95\% Cl 1.46-2.91), gastrostomy (aHR 1.55, 95\% Cl 1.14-2.10), male sex (aHR 1.66, 95\% Cl 1.20-2.23), and worse SAH severity 1.51 (95\% Cl 1.04-2.18) were associated with reduced survival.

CONCLUSIONS In this national analysis, $56 \%$ of octogenarians with SAH died, and $36 \%$ returned home within 1 year of $\mathrm{SAH}$. Coil embolization predicted returning to home, which may suggest a benefit to endovascular treatment in this patient population.

https://thejns.org/doi/abs/10.3171/2018.3.JNS173057

KEYWORDS age; cerebral aneurysm; clipping; endovascular; Minimum Data Set; long-term outcomes; Medicare; octogenarians; subarachnoid hemorrhage; vascular disorders

$\mathrm{T}$ HE aging of the population in the United States is a well-known demographic trend. By 2050 , it is projected that at least $19 \%$ of the US population will be at least 65 years old-an increase from $12 \%$ in $2005-$ and octogenarians will represent a greater proportion of the national population as well..$^{15}$ The demographic shift is also reflected in the age distribution of patients presenting with aneurysmal subarachnoid hemorrhage (SAH), ${ }^{2}$ and a meta-analysis showed that the mean age of patients with SAH increased between 1973 and $2002 . .^{13}$
There remains a paucity of data evaluating octogenarians treated for SAH, particularly data on the rates of longterm independence, as well as the impact of the treatment modality utilized for aneurysm repair on outcomes. This is partially because octogenarians have largely been excluded from randomized clinical trials in the SAH population. For example, patients older than 80 years were excluded from the Barrow Randomized Aneurysm Trial, ${ }^{10}$ and although the International Subarachnoid Aneurysm Trial did not employ an age cutoff, only 4 octogenarians were en-

ABBREVIATIONS aHR = adjusted hazard ratio; $\mathrm{Cl}=$ confidence interval; CMS = Centers for Medicare \& Medicaid Services; ICD-9-CM = International Classification of Diseases, 9th Revision, Clinical Modification; NIS = Nationwide Inpatient Sample; NIS-SSS = NIS SAH Severity Score; SAH = subarachnoid hemorrhage.

SUBMITTED December 5, 2017. ACCEPTED March 12, 2018.

INCLUDE WHEN CITING Published online August 17, 2018; DOI: 10.3171/2018.3.JNS173057. 
rolled. ${ }^{11}$ Therefore, the applicability of these trials to octogenarian patients remains unknown. While additional data on the long-term outcomes of SAH in octogenarians would inform treatment decisions and augment prognostication, it is unlikely that future randomized trials will include very elderly adults. Moreover, few single-institution studies accrue a sufficient population to provide an appropriately powered analysis of outcomes among octogenarians. Therefore, large national data sets are of particular importance and provide a niche in examining the outcomes of this patient population.

The Centers for Medicare \& Medicaid Services (CMS) Fee-for-Service Part A inpatient claims files include data on the hospitalization of all Americans aged at least 65 years. Additionally, the Minimum Data Set accrues detailed assessments of all nursing home residents in the United States. Linking these two data sets provides a unique perspective on the long-term survival and institutional care use of older adults in the United States. Previous analyses have identified time at home and free of institutional care as important patient-centered outcomes among stroke patients. ${ }^{5,16,24}$ Therefore, the goal of this analysis was to 1) evaluate the disposition (living at home vs institutional settings) of octogenarians at up to 2 years after $\mathrm{SAH}$; and 2) analyze the predictors of long-term survival and return to home up to 1 year after SAH. As prior studies have shown that the severity of the initial hemorrhage is the strongest predictor of a poor short-term outcome in older patients with $\mathrm{SAH},{ }^{12}$ it was hypothesized that patient comorbidities and severity of SAH - but not treatment modality used for aneurysm repair-would be the primary predictors of long-term outcomes.

\section{Methods}

\section{Data Source and Inclusion Criteria}

Data were extracted from the $100 \%$ Fee-for-Service Medicare claims denominator file and the corresponding Part A Inpatient Standard Analytical Files from January 1, 2008, to December 31, 2011; the last year of inclusion was 2011 to allow for 2-year follow-up of the entire patient population. Patients were included if they 1) had an International Classification of Diseases, 9th Revision, Clinical Modification (ICD-9-CM) diagnosis code of subarachnoid hemorrhage (430); 2) underwent cerebral aneurysm repair by either microsurgical clipping (39.51) or endovascular embolization $(39.72,39.75,39.76,39.79)$ during the same hospitalization; and 3) were at least 80 years old on the day of admission. Patients were excluded with a diagnosis code indicating a congenital cerebrovascular malformation (747.81, often used to indicate arteriovenous malformations), cerebral arteritis (437.4), or moyamoya disease (437.5) or a procedure code for treatment of an arteriovenous malformation surgically (39.53) or via stereotactic radiosurgery (923.x). Moreover, those who underwent both clipping and coiling during the same hospitalization $(n=14)$ were excluded, to allow for dichotomous analysis of treatment modality.

Thereafter, to determine long-term survival and institutional care utilization, patients from the Medicare Part A files were linked to the Minimum Data Set and the
CMS vital status file using their Medicare health insurance claim number, Social Security number, sex, and date of birth. The vital status file provides data on the date of death and the Minimum Data Set on nursing home utilization. Detailed methods for creating this per-person longitudinal record of healthcare utilization have been described previously. ${ }^{7}$ Analysis was covered by a data use agreement with CMS, and IRB approval was waived by the Brown University IRB.

\section{Independent Variables}

Patient age (analyzed continuously), sex, race or ethnicity (non-Hispanic Caucasian, African American, Hispanic and Asian, other, or not recorded), and socioeconomic status (evaluated by quartile of income in the patient's Zone Improvement Plan [ZIP] code of residence) were extracted. Comorbidities were assessed as the total number of comorbidities documented using the Elixhauser score (range $0-28$, with higher scores indicating greater comorbidity). ${ }^{3}$

A Nationwide Inpatient Sample (NIS) SAH Severity Score (NIS-SSS) ${ }^{22}$ was calculated for each patient and utilized to adjust for the severity of presentation with SAH. The validated NIS-SSS ranges from 0 to 15, with higher scores indicating greater severity for use with administrative claims databases, and prior publications have shown that higher score has a strong concordance with greater Hunt-Hess grade. ${ }^{22}$ The scale is constructed using the ICD-9-CM diagnosis codes for coma, hydrocephalus, hemiparesis, aphasia, and cranial nerve deficits, and procedure codes for cerebrospinal fluid diversion procedures (ventriculostomy and ventricular shunt placement) and mechanical ventilation. Prior studies have shown that the mean NIS-SSS of patients with Hunt and Hess grade 3 was 4, the mean NIS-SSS of those with Hunt and Hess grade 4 was 7.5, and the mean NIS-SSS of those with Hunt and Hess grade 5 was $9 .^{22}$ The treatment modality used for aneurysm obliteration (microsurgical clipping or endovascular embolization), placement of a tracheostomy $(311,312.1$, $312.9)$ and gastrostomy or jejunostomy $(431.1,431.9,463.2)$ during the SAH hospitalization, and the length of stay of the SAH hospitalization were analyzed. Finally, any prior hospitalization in the year before the index admission for SAH was extracted from Medicare Part A claims.

\section{Outcomes}

The primary outcome for the analysis was the disposition of patients at $30,60,365$, and 730 days after admission for SAH. Disposition was defined as the proportion of patients in the following categories: 1) death or hospice enrollment, 2) inpatient acute care hospital, 3) institutional care (inclusive of all rehabilitation and skilled nursing facilities), and 4) returned home. The time points were chosen to provide a description of both short- and long-term outcomes. For multivariable regression, short- and longterm outcomes were modeled at 60 and 365 days, with the dependent variable dichotomized as either 1) death, hospice, or institutionalization or 2) return home. Cox modeling of survival was limited to 365 days after index SAH. 
TABLE 1. Clinical and demographic characteristics of the study population stratified by the treatment modality used for aneurysm repair

\begin{tabular}{|c|c|c|c|c|}
\hline Characteristic & Total Population $(n=1298)$ & Coil Embolization $(n=1010)$ & Microsurgical Clipping $(n=288)$ & $p$ Value \\
\hline Age, mean (SD) & $84.7(3.5)$ & $84.9(3.5)$ & $84.2(3.3)$ & 0.002 \\
\hline Age group & & & & 0.01 \\
\hline $80-84$ yrs & $59(771)$ & $57(578)$ & $67(193)$ & \\
\hline $85-89$ yrs & $32(425)$ & $35(352)$ & $26(73)$ & \\
\hline $90-94$ yrs & $7(88)$ & $7(68)$ & $7(20)$ & \\
\hline $95-100$ yrs & $1(13)$ & $1(12)$ & $-(-)$ & \\
\hline Female sex & $82(1068)$ & $82(831)$ & $82(237)$ & 0.99 \\
\hline Race or ethnicity & & & & 0.08 \\
\hline Caucasian & 77 (996) & $78(785)$ & $73(211)$ & \\
\hline African American & $9(115)$ & $9(93)$ & $7(22)$ & \\
\hline Hispanic & $7(93)$ & $7(66)$ & $9(27)$ & \\
\hline Other or unknown & $7(93)$ & $7(66)$ & $10(27)$ & \\
\hline Socioeconomic status & & & & 0.11 \\
\hline Lower quartile & $24(312)$ & $24(238)$ & $26(74)$ & \\
\hline 2nd quartile & $25(319)$ & $24(242)$ & $26(77)$ & \\
\hline 3rd quartile & $24(319)$ & $26(261)$ & $19(58)$ & \\
\hline Upper quartile & 27 (353) & 27 (269) & $29(84)$ & \\
\hline No. of comorbidities, mean (SD) & $2.1(1.2)$ & $2.1(1.2)$ & $2.1(1.2)$ & 0.64 \\
\hline NIS-SSS, mean (SD) & $6.2(10.6)$ & $6.1(10.6)$ & $6.5(10.8)$ & 0.59 \\
\hline Poor grade (NIS-SSS $\geq 7$ ) & $23(296)$ & $23.9(241)$ & $19(55)$ & 0.16 \\
\hline Tracheostomy & $12(153)$ & $10(102)$ & $18(51)$ & $<0.001$ \\
\hline Gastrostomy & $14(180)$ & $13(127)$ & $19(53)$ & 0.008 \\
\hline Hospitalization during prior year & $32(421)$ & $34(341)$ & $27(80)$ & 0.04 \\
\hline LOS during SAH hospitalization, mean (SD) & $15(10.4)$ & 14.3 & 17.3 & $<0.001$ \\
\hline
\end{tabular}

LOS = length of stay; NIS-SSS = Nationwide Inpatient Sample SAH Severity Score; SAH = subarachnoid hemorrhage; $-=$ data suppressed in accordance with CMS cell size suppression policy.

All data are presented as percentages rounded to the nearest whole number, with the exception of patient age, number of comorbidities, NIS-SSS, and length of stay. Column percentages may not add to 100 due to rounding. Boldface type indicates statistically significant differences in bivariate analyses.

\section{Sensitivity Analysis}

A sensitivity analysis was performed to further evaluate the severity adjustment estimated by the NIS-SSS. This was performed using the individual components of the NIS-SSS (rather than the composite score) as covariates in regression models.

\section{Statistical Analysis}

Statistical analyses were conducted in STATA 13 (StataCorp) and SAS 9.3 (SAS Institute). Descriptive statistics were performed. Thereafter, multivariable models were constructed: due to their clinical relevance, all potential predictors evaluated were included in models as covariates. Furthermore, interaction terms accounting for the treatment modality used for aneurysm repair and NISSSS dichotomized as poor grade (NIS-SSS > 7) or good grade. Cox proportional hazards models were used to analyze survival (after accounting for time to death), while logistic regression assessed the dichotomous outcome of return to home; both models were constructed at the 3 selected time points $(30,60,365$ days) after SAH admission. Patients who died during the SAH hospitalization were not included in the risk set for the Cox proportional hazards models, and therefore only post-hospitalization survival was analyzed in these models. Concordance statistics (c-statistics) were used to evaluate model discriminatory capacity. A probability value less than 0.05 was deemed statistically significant.

\section{Results \\ Demographics of the Study Population}

A total of 1298 patients with SAH who were aged at least 80 years were evaluated, in whom $77.8 \%(n=1010)$ underwent coil embolization. Among the total cohort, $77.1 \%$ were good grade (NIS-SSS < 7), and $22.9 \%$ were poor grade (NIS-SSS $\geq 7$ ). The demographics of the study population are depicted and stratified by the treatment modality used for aneurysm repair in Table 1 . The most common comorbidities from the Elixhauser index were hypertension (47.4\%), fluid and electrolyte disorders (45.6\%), weight loss $(13.6 \%)$, congestive heart failure $(11.0 \%)$, diabetes mellitus $(10.4 \%)$, deficient anemia $(9.4 \%)$, hypothyroidism $(9.0 \%)$, and chronic pulmonary disease $(8.6 \%)$. The proportion of patients with cerebrospinal fluid diversion procedures (included in the NIS-SSS) was $38.7 \%$ for ventriculostomy, and $16.8 \%$ with ventricular shunt placement.

\section{Short-Term and Long-Term Disposition}

At 30 days after SAH, $32.7 \%$ of the cohort had died or were in hospice care, $28.3 \%$ remained hospitalized, $21.1 \%$ were in institutional care, and $16.7 \%$ had returned home. 
TABLE 2. Disposition of the study population at 60,365 , and 730 days after SAH admission, stratified by the treatment modality used for aneurysm repair

\begin{tabular}{|c|c|c|c|}
\hline Group \& Characteristic & $\begin{array}{c}\text { Total } \\
\text { Population }\end{array}$ & $\begin{array}{c}\text { Coil } \\
\text { Embolization }\end{array}$ & $\begin{array}{c}\text { Microsurgical } \\
\text { Clipping }\end{array}$ \\
\hline All patients & $n=1298$ & $n=1010$ & $n=288$ \\
\hline \multicolumn{4}{|l|}{ Disposition at 60 days } \\
\hline Died & $42(549)$ & $42(426)$ & $43(123)$ \\
\hline Home & $26(349)$ & $29(292)$ & $19(56)$ \\
\hline Inpatient & $7(100)$ & $6(64)$ & $13(36)$ \\
\hline Institutional care & $22(284)$ & $21(215)$ & $24(69)$ \\
\hline Hospice & $1(12)$ & $-(-)$ & $-(-)$ \\
\hline \multicolumn{4}{|l|}{ Disposition at 365 days } \\
\hline Died & $55(713)$ & $54(543)$ & $59(169)$ \\
\hline Home & $37(476)$ & $38(382)$ & $32(94)$ \\
\hline Inpatient & $-(-)$ & $-(-)$ & $-(-)$ \\
\hline Institutional care & $7(87)$ & $7(66)$ & $8(22)$ \\
\hline Hospice & $1(12)$ & $1(11)$ & $0(0)$ \\
\hline \multicolumn{4}{|l|}{ Disposition at 730 days } \\
\hline Died & $60(774)$ & $59(598)$ & $61(175)$ \\
\hline Home & $34(443)$ & $35(354)$ & $31(89)$ \\
\hline Inpatient & $-(-)$ & $-(-)$ & $-(-)$ \\
\hline Institutional care & $5(64)$ & $4(42)$ & $7(21)$ \\
\hline Hospice & $-(-)$ & $1(11)$ & $-(-)$ \\
\hline Patients w/ good SAH grade & $n=1001$ & $n=769$ & $n=232$ \\
\hline \multicolumn{4}{|l|}{ Disposition at 60 days } \\
\hline Died & $37(368)$ & $36(274)$ & $41(94)$ \\
\hline Home & $33(331)$ & $37(281)$ & $23(53)$ \\
\hline Inpatient & $6(63)$ & $5(39)$ & $10(24)$ \\
\hline Institutional care & $23(234)$ & $23(173)$ & $26(60)$ \\
\hline Hospice & $-(-)$ & $-(-)$ & $0(0)$ \\
\hline \multicolumn{4}{|l|}{ Disposition at 365 days } \\
\hline Died & 49 (492) & $47(364)$ & $55(128)$ \\
\hline Home & $43(426)$ & $45(343)$ & $36(83)$ \\
\hline Inpatient & $-(-)$ & $-(-)$ & $0(0)$ \\
\hline Institutional care & $7(68)$ & $6(48)$ & $9(20)$ \\
\hline Hospice & $-(-)$ & $-(-)$ & $0(0)$ \\
\hline \multicolumn{4}{|l|}{ Disposition at 730 days } \\
\hline Died & $54(539)$ & $53(406)$ & $57(132)$ \\
\hline Home & $39(394)$ & $41(316)$ & $34(78)$ \\
\hline Inpatient & $-(-)$ & $-(-)$ & $-(-)$ \\
\hline Institutional care & $5(52)$ & $4(33)$ & $8(19)$ \\
\hline Hospice & $1(11)$ & $-(-)$ & $-(-)$ \\
\hline Patients w/ poor SAH grade & $n=297$ & $n=241$ & $n=56$ \\
\hline \multicolumn{4}{|l|}{ Disposition at 60 days } \\
\hline Died & $61(181)$ & $63(152)$ & $52(29)$ \\
\hline Home & $7(22)$ & $8(18)$ & $-(-)$ \\
\hline Inpatient & $6(19)$ & $5(12)$ & $-(-)$ \\
\hline Institutional care & $17(51)$ & $17(42)$ & $-(-)$ \\
\hline Hospice & $-(-)$ & $-(-)$ & $-(-)$ \\
\hline
\end{tabular}

» CONTINUED FROM PREVOUS COLUMN

TABLE 2. Disposition of the study population at 60,365 , and 730 days after SAH admission, stratified by the treatment modality used for aneurysm repair

\begin{tabular}{cccc}
\hline Group \& Characteristic & $\begin{array}{c}\text { Total } \\
\text { Population }\end{array}$ & $\begin{array}{c}\text { Coil } \\
\text { Embolization }\end{array}$ & $\begin{array}{c}\text { Microsurgical } \\
\text { Clipping }\end{array}$ \\
\hline $\begin{array}{c}\text { Patients w/ poor SAH grade } \\
\text { (continued) }\end{array}$ & $\mathrm{n}=297$ & $\mathrm{n}=241$ & $\mathrm{n}=56$ \\
\hline $\begin{array}{c}\text { Disposition at 365 } \\
\text { days }\end{array}$ & & & \\
\hline Died & $74(221)$ & $74(179)$ & $75(42)$ \\
\hline Home & $18(53)$ & $17(42)$ & $20(11)$ \\
\hline Inpatient & $-(-)$ & $-(-)$ & $-(-)$ \\
\hline Institutional care & $7(20)$ & $6(15)$ & $-(-)$ \\
\hline Hospice & $-(-)$ & $-(-)$ & $0(0)$ \\
\hline $\begin{array}{c}\text { Disposition at 730 } \\
\text { days }\end{array}$ & & & \\
\hline Died & $79(235)$ & $80(192)$ & $77(43)$ \\
\hline Home & $16(48)$ & $15(37)$ & $20(11)$ \\
\hline Inpatient & $0(0)$ & $-(-)$ & $0(0)$ \\
\hline Institutional care & $4(11)$ & $-(-)$ & $-(-)$ \\
\hline Hospice & $-(-)$ & $-(-)$ & $0(0)$ \\
\hline
\end{tabular}

- = data suppressed in accordance with CMS cell size suppression policy. All data are presented as percentages, rounded to the nearest whole number, of the entire cohort (complete case analysis) without missing data at each follow-up interval. Column percentages may not add to 100 due to rounding.

The 60-, 365-, and 730-day disposition of patients is presented in Table 2 for the total study population as well as the population stratified by both the treatment modality used for aneurysm treatment and SAH severity. Institutional care of octogenarian patients at 1 and 2 years after SAH was rare. This is illustrated by Fig. 1, displaying primary outcomes of patient death/hospice care, return to home, or institutional care (i.e., inpatient acute hospital,

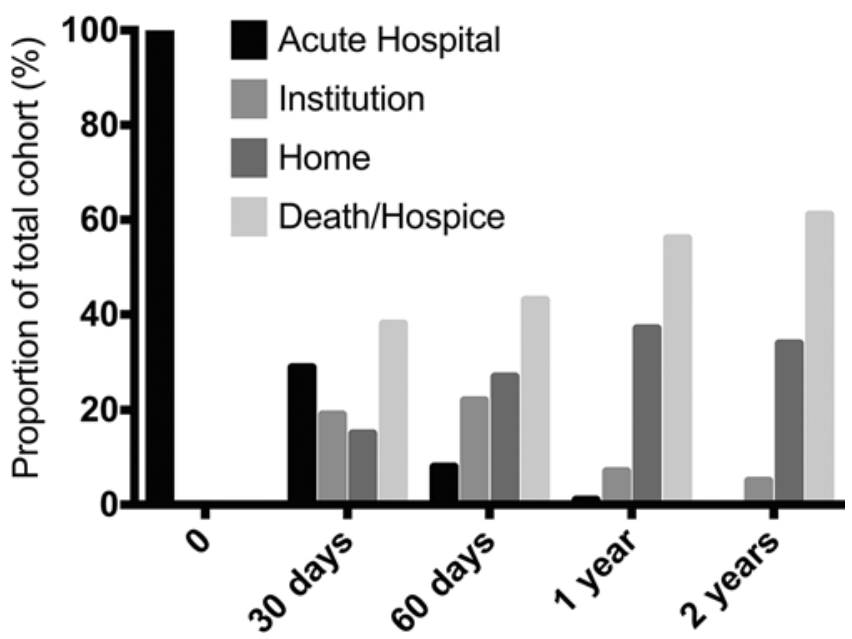

FIG. 1. Disposition of the entire study population over the 2-year study period. Black indicates acute hospital care. Gray indicates institutional care (i.e., rehabilitation, nursing home/skilled nursing facility). Dark gray indicates return to home. Lightest gray indicates death/hospice care. 


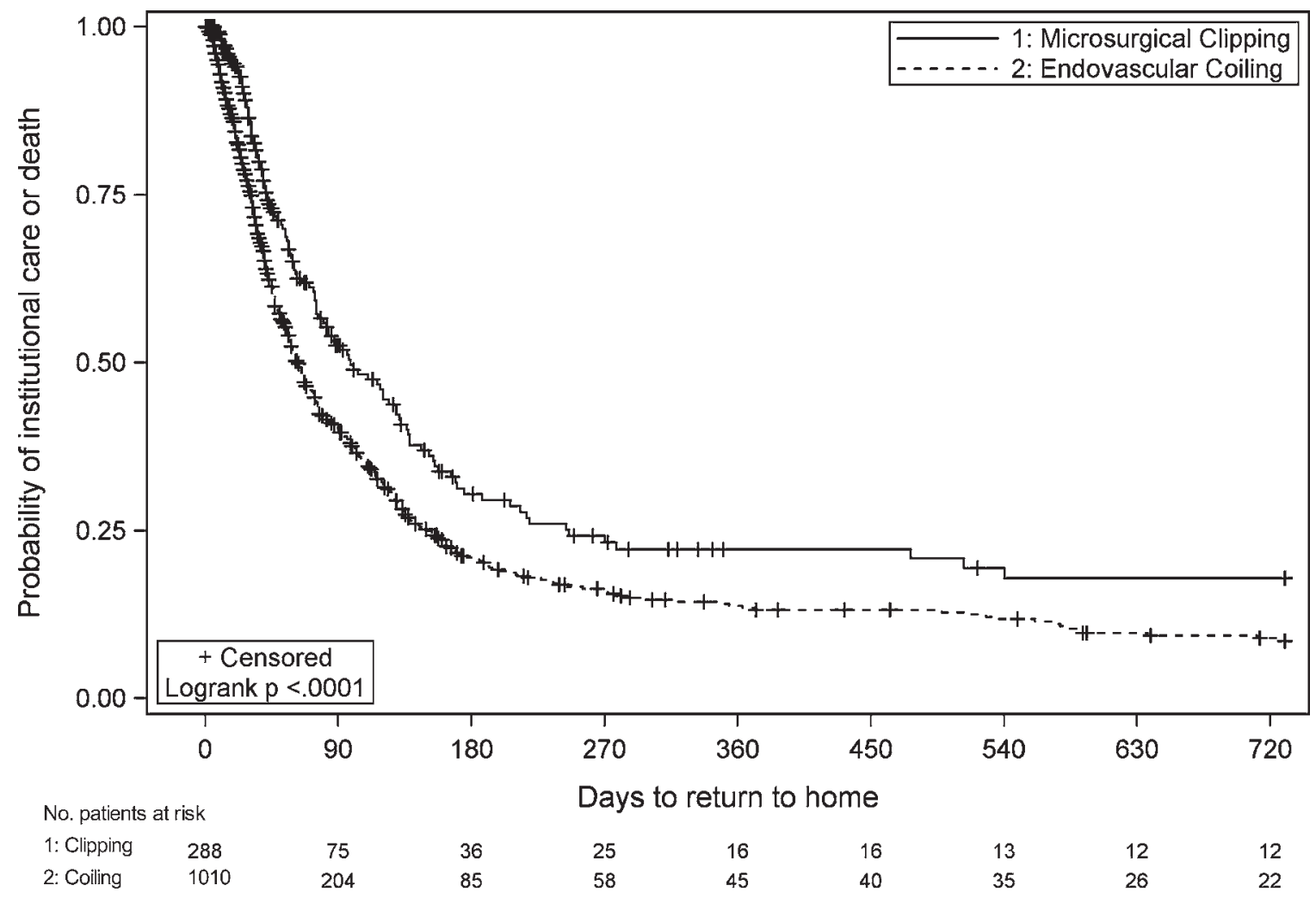

FIG. 2. Kaplan-Meier time-to-event curves comparing microsurgical clipping and endovascular coiling. The entire cohort was hospitalized at the time of aneurysm treatment. Mortality and institutional care at any location other than home (acute hospital, rehabilitation, nursing home/skilled nursing facility) were combined for the analysis. Time to return home was significantly less for the endovascular coiling group than for the microsurgical clipping group $(p<0.0001)$.

rehabilitation, or skilled nursing facility care) at presentation and 30, 60, 365, and 730 days after admission. At 2 years after $\mathrm{SAH}, 34.1 \%$ of patients had returned to home, including $35.0 \%$ of patients treated with coil embolization and $30.9 \%$ of those treated with microsurgical clipping. Figure 2 displays Kaplan-Meier time-to-event curves comparing time to return home between patients treated with microsurgical clipping and those treated with endovascular coiling. Time to return home was significantly less for the endovascular coiling group than for the microsurgical clipping group $(\mathrm{p}<0.0001)$.

Among patients institutionalized 60 days after SAH, the long-term disposition was specifically evaluated, to analyze how many of these patients ultimately returned home. At 365 days after SAH, 36.6\% had died or were in hospice, $43.3 \%$ had returned home, $19.3 \%$ remained in institutional care, and $1.0 \%$ were inpatients. At 730 days after hemorrhage, $46.1 \%$ had died or were in hospice, $40.0 \%$ had returned home, $13.5 \%$ were institutionalized, and $0.5 \%$ were inpatients.

\section{Survival Analysis}

Multivariable Cox proportional hazards models evaluated the predictors of mortality 365 days after admission for SAH (Table 3). Older patient age, male sex, tracheostomy placement, and gastrostomy placement during the $\mathrm{SAH}$ hospitalization were associated with significantly greater hazard of mortality at 1 year after SAH. A sen-
TABLE 3. Cox proportional hazards model evaluating predictors of mortality at 365 days after admission for SAH

\begin{tabular}{|c|c|c|c|}
\hline Characteristic & $\mathrm{HR}$ & $95 \% \mathrm{Cl}$ & p Value \\
\hline Treatment modality & & & 0.11 \\
\hline Endovascular coiling & Ref. & - & \\
\hline Microsurgical clipping & 1.27 & $(0.95-1.68)$ & \\
\hline Age & 1.09 & $(1.05-1.12)$ & $<0.001$ \\
\hline Female sex & 0.63 & $(0.46-0.86)$ & 0.003 \\
\hline Race or ethnicity & & & 0.60 \\
\hline Caucasian & Ref. & - & \\
\hline African American & 0.77 & $(0.49-1.23)$ & \\
\hline Hispanic & 0.80 & $(0.51-1.24)$ & \\
\hline Other or unknown & 0.96 & $(0.59-1.57)$ & \\
\hline Socioeconomic status & & & 0.35 \\
\hline Lower quartile & Ref. & - & \\
\hline 2nd quartile & 0.75 & $(0.51-1.11)$ & \\
\hline 3rd quartile & 1.05 & $(0.73-1.51)$ & \\
\hline Upper quartile & 0.88 & $(0.62-1.29)$ & \\
\hline No. of comorbidities & 1.07 & $(0.96-1.20)$ & 0.24 \\
\hline NIS-SSS & 1.01 & $(0.99-1.03)$ & 0.19 \\
\hline Tracheostomy & 2.11 & $(1.49-2.98)$ & $<0.001$ \\
\hline Gastrostomy & 1.54 & $(1.13-2.09)$ & 0.006 \\
\hline Hospitalization during prior year & 0.95 & $(0.72-1.26)$ & 0.72 \\
\hline LOS during SAH hospitalization & 1.02 & $(1.00-1.03)$ & 0.009 \\
\hline
\end{tabular}

Boldface type indicates statistically significant differences in multivariable Cox proportional hazards model. 
TABLE 4. Cox proportional hazards model evaluating predictors of return to home at 365 days after admission for SAH

\begin{tabular}{|c|c|c|c|}
\hline Characteristic & HR & $95 \% \mathrm{Cl}$ & $p$ Value \\
\hline Treatment modality & & & $<0.001$ \\
\hline Endovascular coiling & Ref. & - & \\
\hline Microsurgical clipping & 0.67 & $(0.54-0.081)$ & \\
\hline Age & 0.98 & $(0.95-1.00)$ & 0.07 \\
\hline Male sex & 0.70 & $(0.57-0.87)$ & 0.003 \\
\hline Race or ethnicity & & & 0.51 \\
\hline Caucasian & Ref. & - & \\
\hline African American & 0.91 & $(0.69-1.20)$ & \\
\hline Hispanic & 1.31 & $(0.99-1.73)$ & \\
\hline Other or unknown & 1.07 & $(0.79-1.47)$ & \\
\hline Socioeconomic status & & & $<0.05$ \\
\hline Lower quartile & Ref. & - & \\
\hline 2nd quartile & 1.21 & $(0.96-1.52)$ & \\
\hline 3rd quartile & 1.18 & $(0.93-1.50)$ & \\
\hline Upper quartile & 1.40 & $(1.11-1.78)$ & \\
\hline No. of comorbidities & 0.95 & $(0.89-1.02)$ & 0.13 \\
\hline NIS-SSS & 0.94 & $(0.92-0.97)$ & $<0.05$ \\
\hline Tracheostomy & 0.63 & $(0.47-0.85)$ & $<0.001$ \\
\hline Gastrostomy & 0.60 & $(0.48-0.76)$ & $<0.001$ \\
\hline Hospitalization during prior year & 0.93 & $(0.79-1.11)$ & 0.64 \\
\hline LOS during SAH hospitalization & 0.96 & $(0.95-0.97)$ & $<0.05$ \\
\hline
\end{tabular}

Boldface type indicates statistically significant differences in multivariable Cox proportional hazards model.

sitivity analysis used the components of the NIS-SSS as individual covariates, which showed similar statistical associations with the primary analysis (data not shown), and none of the individual components of the score were significantly associated with survival.

\section{Return to Home}

Cox proportional hazards modeling identified microsurgical clipping, male sex, greater severity, tracheostomy, gastrostomy, and longer length of stay to be associated with reduced likelihood of returning home by 365 days after SAH (Table 4). Multivariable logistic regression models evaluated the predictors of return to home at 60 and 365 days after admission for SAH (Table 5). The final models included interaction terms for treatment modality used for aneurysm repair and NIS-SSS. The same associations are provided without interaction terms in Table 6. Microsurgical clipping was associated with reduced odds of return to home among patients with good-grade $\mathrm{SAH}$, but treatment modality used for aneurysm repair was not significantly associated with disposition among patients with poor-grade SAH. In addition, older patient age, tracheostomy, and shorter SAH hospitalization were associated with reduced odds of return to home at 60 and 365 days after SAH with moderate discriminatory capacity (cstatistic: 0.75 and 0.69 , respectively).

A sensitivity analysis using the individual components of the NIS-SSS as covariates, rather than the composite score, revealed similar associations for the primary analysis among covariates (data not shown).

TABLE 5. Multivariable logistic regression models evaluating the predictors of return to home at 60 and 365 days after admission for SAH, accounting for the interaction between severity of SAH and treatment modality used for aneurysm repair

\begin{tabular}{|c|c|c|c|}
\hline Characteristic & OR & $95 \% \mathrm{Cl}$ & $\mathrm{p}$ Value \\
\hline \multicolumn{4}{|l|}{60 days after $\mathrm{SAH}$} \\
\hline $\begin{array}{l}\text { Treatment modality among patients } \\
\text { w/ good SAH grade }\end{array}$ & & & 0.003 \\
\hline Endovascular coiling & Ref. & - & \\
\hline Microsurgical clipping & 0.41 & $(0.25-0.67)$ & \\
\hline \multicolumn{4}{|l|}{$\begin{array}{l}\text { Treatment modality among patients } \\
\text { w/ poor SAH grade }\end{array}$} \\
\hline Endovascular coiling & Ref. & - & \\
\hline Microsurgical clipping & 3.36 & $(0.94-12.08)$ & \\
\hline \multicolumn{4}{|l|}{$\begin{array}{l}\text { SAH grade among endovascular } \\
\text { patients }\end{array}$} \\
\hline Poor & Ref. & - & \\
\hline Good & 6.59 & $(3.15-13.78)$ & \\
\hline \multicolumn{4}{|l|}{$\begin{array}{l}\text { SAH grade among microsurgical } \\
\text { patients }\end{array}$} \\
\hline Poor & Ref. & - & \\
\hline Good & 0.8 & $(0.25-2.55)$ & \\
\hline Age & 0.92 & $(0.87-0.96)$ & $<0.001$ \\
\hline Female sex & 1.04 & $(0.67-1.61)$ & 0.86 \\
\hline Race or ethnicity & & & 0.50 \\
\hline Caucasian & Ref. & - & \\
\hline African American & 0.91 & $(0.46-1.78)$ & \\
\hline Hispanic & 1.46 & $(0.78-2.74)$ & \\
\hline Other or unknown & 0.75 & $(0.39-1.47)$ & \\
\hline Socioeconomic status & & & 0.02 \\
\hline Lower quartile & Ref. & - & \\
\hline 2nd quartile & 1.05 & $(0.63-1.76)$ & \\
\hline 3rd quartile & 1.62 & $(0.99-2.65)$ & \\
\hline Upper quartile & 1.84 & $(1.13-2.99)$ & \\
\hline No. of comorbidities & 1.05 & $(0.91-1.21)$ & 0.49 \\
\hline Tracheostomy & 0.15 & $(0.04-0.65)$ & 0.01 \\
\hline Gastrostomy & 0.17 & $(0.06-0.48)$ & $<0.001$ \\
\hline Hospitalization during prior year & 1.03 & $(0.73-1.46)$ & 0.85 \\
\hline LOS during SAH hospitalization & 0.99 & $(0.97-1.08)$ & 0.18 \\
\hline C-statistic & 0.75 & & \\
\hline \multicolumn{4}{|l|}{365 days after $\mathrm{SAH}$} \\
\hline $\begin{array}{l}\text { Treatment modality among patients } \\
\text { w/ good SAH grade }\end{array}$ & & & 0.09 \\
\hline Endovascular coiling & Ref. & - & \\
\hline Microsurgical clipping & 0.64 & $(0.46-0.89)$ & \\
\hline \multicolumn{4}{|l|}{$\begin{array}{l}\text { Treatment modality among patients } \\
\text { w/ poor SAH grade }\end{array}$} \\
\hline Endovascular coiling & Ref. & - & \\
\hline Microsurgical clipping & 1.33 & $(0.62-2.85)$ & \\
\hline \multicolumn{4}{|l|}{$\begin{array}{l}\text { SAH grade among endovascular } \\
\text { patients }\end{array}$} \\
\hline Poor & Ref. & - & \\
\hline Good & 3.46 & $(2.35-5.09)$ & \\
\hline \multicolumn{4}{|l|}{$\begin{array}{l}\text { SAH grade among microsurgical } \\
\text { patients }\end{array}$} \\
\hline Poor & Ref. & - & \\
\hline Good & 1.67 & $(0.80-3.51)$ & \\
\hline
\end{tabular}


» CONTINUED FROM PAGE 431

TABLE 5. Multivariable logistic regression models evaluating the predictors of return to home at 60 and 365 days after admission for SAH, accounting for the interaction between severity of SAH and treatment modality used for aneurysm repair

\begin{tabular}{lccc}
\hline \multicolumn{1}{c}{ Characteristic } & OR & $95 \% \mathrm{Cl}$ & $\mathrm{p} \mathrm{Value}$ \\
\hline 365 days after SAH (continued) & & & \\
\hline Age & 0.90 & $(0.86-0.93)$ & $<0.001$ \\
\hline Female sex & 1.30 & $(0.94-1.80)$ & 0.12 \\
\hline Race or ethnicity & & & 0.79 \\
$\quad$ Caucasian & Ref. & - & \\
$\quad$ African American & 1.20 & $(0.73-1.89)$ & \\
Hispanic & 1.17 & $(0.69-1.88)$ & \\
$\quad$ Other or unknown & 1.11 & $(0.94-1.80)$ & \\
Socioeconomic status & & & 0.11 \\
$\quad$ Lower quartile & Ref. & - & \\
2nd quartile & 1.40 & $(0.98-2.00)$ & \\
3rd quartile & 1.08 & $(0.75-1.56)$ & \\
$\quad$ Upper quartile & 1.43 & $(1.00-2.05)$ & \\
\hline No. of comorbidities & 1.06 & $(0.95-1.17)$ & 0.33 \\
\hline Tracheostomy & $\mathbf{0 . 5 3 2}$ & $(0.32-0.84)$ & 0.008 \\
\hline Gastrostomy & $\mathbf{0 . 6 4}$ & $(0.43-0.96)$ & 0.03 \\
\hline Hospitalization during prior year & 0.78 & $(0.60-1.01)$ & 0.06 \\
\hline LOS during SAH hospitalization & 1.03 & $(1.01-1.04)$ & $<0.001$ \\
\hline C-statistic & 0.69 & & \\
\hline Bo & & & \\
\hline
\end{tabular}

Boldface type indicates statistically significant differences from multivariable logistic regression model.

\section{Discussion}

This nationwide study demonstrates a low rate of chronic institutionalization and a high rate of mortality among octogenarians after SAH. Although a substantial proportion of patients were institutionalized or died during the early post-acute care period, long-term trends reveal most patients ultimately return home or die within the first 2 years after SAH. Stratified by treatment modality, the independent variables of greater age, male sex, SAH severity, tracheostomy, and gastrostomy were all associated with lower odds of survival and returning home. Coil embolization was a predictor of returning home, suggesting a benefit to endovascular treatment in this nonrandomized analysis of this patient population.

This study enhances understanding where few previous studies have specifically examined the outcomes of SAH treatment for very elderly patients. Some authors have reported comparatively favorable outcomes among this patient population. Horiuchi et al. reported a $54.1 \%$ rate of good short-term outcome (as measured by the Glasgow Outcome Scale); predictors of a poor outcome in their study were greater SAH grade and anterior cerebral artery location, but not patient age. ${ }^{6}$ Likewise, others have observed high rates of good outcomes among octogenarians treated endovascularly. ${ }^{17,23}$

However, not all authors argue that very elderly patients with SAH should be offered treatment. In 2011, Koffijberg et al. proposed a Markov model of the cost-effectiveness of aneurysm treatment in elderly patients and argued that
TABLE 6. Logistic regression model evaluating predictors of return to home at 60 and 365 days after admission for SAH

\begin{tabular}{|c|c|c|c|}
\hline Characteristic & OR & $95 \% \mathrm{Cl}$ & p Value \\
\hline \multicolumn{4}{|l|}{60 days after $\mathrm{SAH}$} \\
\hline Treatment modality & & & 0.004 \\
\hline Endovascular coiling & Ref. & - & \\
\hline Microsurgical clipping & 0.50 & $(0.31-0.80)$ & \\
\hline Age & 0.92 & $(0.88-0.97)$ & 0.001 \\
\hline Female sex & 1.01 & $(0.65-1.57)$ & 0.96 \\
\hline Race or ethnicity & & & 0.48 \\
\hline Caucasian & Ref. & - & \\
\hline African American & 0.91 & $(0.46-1.81)$ & \\
\hline Hispanic & 1.51 & $(0.80-2.87)$ & \\
\hline Other or unknown & 0.76 & $(0.38-1.50)$ & \\
\hline Socioeconomic status & & & 0.04 \\
\hline Lower quartile & Ref. & - & \\
\hline 2nd quartile & 1.01 & $(0.60-1.70)$ & \\
\hline 3rd quartile & 1.61 & $(0.98-2.66)$ & \\
\hline Upper quartile & 1.72 & $(1.05-2.82)$ & \\
\hline No. of comorbidities & 1.01 & $(0.87-1.16)$ & 0.93 \\
\hline NIS-SSS & 0.75 & $(0.69-0.81)$ & $<0.001$ \\
\hline Tracheostomy & 0.23 & $(0.05-0.98)$ & 0.047 \\
\hline Gastrostomy & 0.18 & $(0.06-0.52)$ & 0.001 \\
\hline Hospitalization during prior year & 0.98 & $(0.69-1.40)$ & 0.92 \\
\hline LOS during SAH hospitalization & 0.99 & $(0.97-1.01)$ & 0.39 \\
\hline Concordance statistic & 0.79 & & \\
\hline \multicolumn{4}{|l|}{365 days after $\mathrm{SAH}$} \\
\hline Treatment modality & & & 0.04 \\
\hline Endovascular coiling & Ref. & - & \\
\hline Microsurgical clipping & 0.72 & $(0.53-0.98)$ & \\
\hline Age & 0.90 & $(0.86-0.93)$ & $<0.001$ \\
\hline Female sex & 1.28 & $(0.92-1.79)$ & 0.14 \\
\hline Race or ethnicity & & & 0.83 \\
\hline Caucasian & Ref. & - & \\
\hline African American & 1.17 & $(0.71-1.85)$ & \\
\hline Hispanic & 1.15 & $(0.69-1.84)$ & \\
\hline Other or unknown & 1.13 & $(0.92-1.79)$ & \\
\hline Socioeconomic status & & & 0.18 \\
\hline Lower quartile & Ref. & - & \\
\hline 2nd quartile & 1.35 & $(0.94-1.93)$ & \\
\hline 3rd quartile & 1.05 & $(0.73-1.52)$ & \\
\hline Upper quartile & 1.37 & $(0.95-1.96)$ & \\
\hline No. of comorbidities & 1.04 & $(0.93-1.16)$ & 0.50 \\
\hline NIS-SSS & 0.86 & $(0.83-0.90)$ & $<0.001$ \\
\hline Tracheostomy & 0.61 & $(0.37-0.99)$ & 0.04 \\
\hline Gastrostomy & 0.65 & $(0.43-0.97)$ & 0.04 \\
\hline Hospitalization during prior year & 0.76 & $(0.58-0.99)$ & 0.04 \\
\hline LOS during SAH hospitalization & 0.9003 & $(0.86-0.93)$ & $<0.001$ \\
\hline Concordance statistic & 0.72 & & \\
\hline
\end{tabular}

Boldface type indicates statistically significant differences from multivariable logistic regression model.

beyond 80 years of age, the balance of risk and benefit did not favor aneurysm occlusion. ${ }^{9}$ Others have found low rates of survival and favor caution in pursuing surgical 
treatment. ${ }^{4,14,18}$ Prior analysis of the Nationwide Inpatient Sample has shown that very elderly adults are increasingly being treated with endovascular embolization in the United States, ${ }^{1}$ and in this setting additional data evaluating the long-term outcomes of octogenarians are needed.

Our study is unique in its use of $100 \%$ Medicare Part A inpatient files linked to the Minimum Data Set, which provides a nationally representative examination of longterm disposition and survival of octogenarians treated for aneurysmal SAH. There is a substantial increase (17\%) in mortality between 30 days and 1 year in this patient population, highlighting the fact that many deaths occur posthospitalization. However, among survivors of SAH, only a small minority remained institutionalized in the long term $-6.7 \%$ at 1 year and $4.1 \%$ at 2 years after SAH. Moreover, $36.7 \%$ of patients had returned to home at 1 year and $34.1 \%$ at 2 years, emphasizing that good outcomes in this patient population are possible, albeit in appropriately selected patients. While return to home is not as granular an assessment of independence compared with ordinal scales of neurological outcome (such as the Glasgow Outcome Scale), it indicates a level of functional independence that does not require the patient to depend on institutional care. Additionally, return to home is an important clinical endpoint of interest to patients and their families when determining the aggressiveness of care to pursue., ${ }^{5,16,24}$

To identify predictors of long-term survival and return to home, Cox models and multivariable regression models were constructed. Older patient age, male sex, tracheostomy placement, and gastrostomy placement were independently associated with reduced survival at 1 and 2 years after SAH. Tracheostomy and gastrostomy may be proxies for neurological function toward the end of the SAH hospitalization, and the NIS-SSS outcome measure, based on mortality, discharge to institutional care, and tracheostomy or gastrostomy placement, has been shown to have excellent concordance with the modified Rankin Scale in the SAH population..$^{22}$ Additionally, older patient age, higher NIS-SSS (worse SAH grade), the use of microsurgical clipping, and tracheostomy were independently associated with reduced odds of return to home 1 year after SAH.

Clinical decision making for treating octogenarians with SAH presents several unique considerations. While some studies have suggested that older patients with SAH have a lower incidence of symptomatic delayed cerebral ischemia, ${ }^{21}$ several authors have emphasized that older patients sustain inferior long-term outcomes compared with younger patients. ${ }^{8,12,19,20}$ Our findings of SAH clinical grade as an important independent predictor of octogenarians' ability to return home add an important perspective in interpreting previous work.

Limitations to this analysis include: 1) Clinical data are encoded in the Minimum Data Set using ICD-9-CM identifiers. While severity adjustment was estimated using the NIS-SSS - which has been externally validated against Hunt and Hess grade-several other noteworthy clinical features in patients with aneurysmal SAH, including WFNS (World Federation of Neurosurgical Societies) score, Fisher grade, aneurysm location or size, and delayed cerebral ischemia, were not available due to the lack of corresponding ICD-9-CM identifiers. 2) Aneurysm size, location, and other characteristics were not available in the data set. If less complicated aneurysms are more frequently selected for endovascular approach, accounting for these factors may reduce the strength of the reported associations between aneurysm treatment and mortality or return to home. 3) Although return to home was analyzed as the primary proxy for a good outcome, the neurological status of such patients, including the modified Rankin Scale or the Glasgow Outcome Scale score, could not be analyzed with the study design. 4) The ICD-9-CM code for SAH does not specify the etiology as aneurysmal or nonaneurysmal, and patients with aneurysmal SAH treated conservatively could not be evaluated.

\section{Conclusions}

This nationally representative analysis of long-term survival and outcomes of very elderly adults with SAH can inform prognostication and may inform treatment decisions. Although rates of long-term institutional care dependence among survivors are low, the high mortality rates emphasize the importance of appropriate patient selection for aneurysm repair. While the treatment modality used for aneurysm occlusion was not associated with survival, endovascular coil embolization was associated with greater odds of return to home at 1 and 2 years after treatment among patients with good-grade SAH. Nevertheless, treatment modality did not significantly impact the outcomes of patients with poor-grade SAH. Although this analysis did not control for aneurysm architecture and location, our results favor endovascular treatment when otherwise clinically appropriate for octogenarian patients with goodgrade $\mathrm{SAH}$. The decisions for managing poor-grade $\mathrm{SAH}$ should be based upon a comprehensive discussion between the patient's family members and clinicians, considering the low probability of long-term survival and return to home.

\section{Acknowledgments}

Dr. Mor is supported by National Institutes of Health (NIH) R01HL111032 and K24AG049057. Dr. Mitchell is supported by NIH-National Institute on Aging K24AG033640. Dr. Fehnel is supported by the American Academy of Neurology Clinical Research Training Fellowship.

\section{References}

1. Brinjikji W, Lanzino G, Rabinstein AA, Kallmes DF, Cloft HJ: Age-related trends in the treatment and outcomes of ruptured cerebral aneurysms: a study of the Nationwide Inpatient Sample 2001-2009. AJNR Am J Neuroradiol 34:1022-1027, 2013

2. de Rooij NK, Linn FHH, van der Plas JA, Algra A, Rinkel GJE: Incidence of subarachnoid haemorrhage: a systematic review with emphasis on region, age, gender and time trends. J Neurol Neurosurg Psychiatry 78:1365-1372, 2007

3. Elixhauser A, Steiner C, Harris DR, Coffey RM: Comorbidity measures for use with administrative data. Med Care 36:8-27, 1998

4. Fridriksson SM, Hillman J, Säveland H, Brandt L: Intracranial aneurysm surgery in the 8th and 9th decades of life: impact on population-based management outcome. Neurosurgery 37:627-632, 1995

5. Hannah D, Lindholm B, Maisch L: Certain uncertainty: life 
after stroke from the patient's perspective. Circ Cardiovasc Qual Outcomes 7:968-969, 2014

6. Horiuchi T, Tsutsumi K, Ito K, Hongo K: Results of clipping surgery for aneurysmal subarachnoid hemorrhage in the ninth and tenth decades of life. J Clin Neurosci 21:15671569,2014

7. Intrator O, Hiris J, Berg K, Miller SC, Mor V: The residential history file: studying nursing home residents' long-term care histories. Health Serv Res 46:120-137, 2011

8. Khosla A, Brinjikji W, Cloft H, Lanzino G, Kallmes DF: Age-related complications following endovascular treatment of unruptured intracranial aneurysms. AJNR Am J Neuroradiol 33:953-957, 2012

9. Koffijberg H, Buskens E, Rinkel GJ: Aneurysm occlusion in elderly patients with aneurysmal subarachnoid haemorrhage: a cost-utility analysis. J Neurol Neurosurg Psychiatry 82:718-727, 2011

10. McDougall CG, Spetzler RF, Zabramski JM, Partovi S, Hills NK, Nakaji P, et al: The Barrow Ruptured Aneurysm Trial. J Neurosurg 116:135-144, 2012

11. Molyneux A, Kerr R, Stratton I, Sandercock P, Clarke M, Shrimpton J, et al: International Subarachnoid Aneurysm Trial (ISAT) of neurosurgical clipping versus endovascular coiling in 2143 patients with ruptured intracranial aneurysms: a randomised trial. Lancet 360:1267-1274, 2002

12. Nieuwkamp DJ, Rinkel GJ, Silva R, Greebe P, Schokking DA, Ferro JM: Subarachnoid haemorrhage in patients $>$ or $=$ 75 years: clinical course, treatment and outcome. J Neurol Neurosurg Psychiatry 77:933-937, 2006

13. Nieuwkamp DJ, Setz LE, Algra A, Linn FHH, de Rooij NK, Rinkel GJE: Changes in case fatality of aneurysmal subarachnoid haemorrhage over time, according to age, sex, and region: a meta-analysis. Lancet Neurol 8:635-642, 2009

14. Park J, Woo H, Kang DH, Kim Y: Critical age affecting 1-year functional outcome in elderly patients aged $\geq 70$ years with aneurysmal subarachnoid hemorrhage. Acta Neurochir (Wien) 156:1655-1661, 2014

15. Passel JS, Cohn D: U.S. Population Projections: 2005-2050. Washington, DC: Pew Research Center, 2008 (http://www.pewhispanic.org/2008/02/11/us-populationprojections-2005-2050/) [Accessed May 4, 2018]

16. Quinn TJ, Dawson J, Lees JS, Chang TP, Walters MR, Lees KR: Time spent at home poststroke: "home-time" a meaningful and robust outcome measure for stroke trials. Stroke 39:231-233, 2008

17. Sadamasa N, Koyanagi M, Fukuda H, Chin M, Handa A, Yamagata $\mathrm{S}$ : Is aneurysm repair justified for the patients aged 80 or older after aneurysmal subarachnoid hemorrhage? J Neurointerv Surg 6:664-666, 2014

18. Schöller K, Massmann M, Markl G, Kunz M, Fesl G, Brückmann $\mathrm{H}$, et al: Aneurysmal subarachnoid hemorrhage in elderly patients: long-term outcome and prognostic factors in an interdisciplinary treatment approach. J Neurol 260:10521060, 2013

19. Sturiale CL, Brinjikji W, Murad MH, Lanzino G: Endovascular treatment of intracranial aneurysms in elderly patients: a systematic review and meta-analysis. Stroke 44:1897-1902, 2013

20. Voeks JH, Howard G, Roubin GS, Malas MB, Cohen DJ, Sternbergh WC III, et al: Age and outcomes after carotid stenting and endarterectomy: the carotid revascularization endarterectomy versus stenting trial. Stroke 42:3484-3490, 2011

21. Wachter D, Hans F, Kreitschmann-Andermahr I, Rohde V: Lower incidence of transcranial Doppler and symptomatic vasospasm after aneurysmal subarachnoid hemorrhage and aneurysm clipping in the elderly patient? Neurosurgery 69:261-267, 2011

22. Washington CW, Derdeyn CP, Dacey RG Jr, Dhar R, Zipfel GJ: Analysis of subarachnoid hemorrhage using the Nationwide Inpatient Sample: the NIS-SAH Severity Score and Outcome Measure. J Neurosurg 121:482-489, 2014

23. Wilson TJ, Davis MC, Stetler WR, Giles DA, Chaudhary N, Gemmete JJ, et al: Endovascular treatment for aneurysmal subarachnoid hemorrhage in the ninth decade of life and beyond. J Neurointerv Surg 6:175-177, 2014

24. Xian Y, O'Brien EC, Fonarow GC, Olson DM, Schwamm LH, Hannah D, et al: Patient-centered research into outcomes stroke patients prefer and effectiveness research: implementing the patient-driven research paradigm to aid decision making in stroke care. Am Heart J 170:36-45, 45.e1-45.e11, 2015

\section{Disclosures}

The authors report no conflict of interest concerning the materials or methods used in this study or the findings specified in this paper.

\section{Author Contributions}

Conception and design: Fehnel, Dasenbrock, Gormley. Acquisition of data: Fehnel. Analysis and interpretation of data: Fehnel, Dasenbrock, Mitchell. Drafting the article: Fehnel, Dasenbrock. Critically revising the article: Fehnel, Gormley, Mitchell. Reviewed submitted version of manuscript: all authors. Approved the final version of the manuscript on behalf of all authors: Fehnel. Statistical analysis: Fehnel, Lee. Administrative/technical/ material support: Gormley, Mor. Study supervision: Gormley, Mor, Mitchell.

\section{Correspondence}

Corey R. Fehnel: Hebrew SeniorLife, Institute for Aging Research, Boston, MA.cfehnel@bidmc.harvard.edu. 